\title{
Effects of Anatomy and Particle Size on Nasal Sprays and Nebulizers
}

\author{
Dennis O. Frank, Ph.D. ${ }^{1}$, Julia S. Kimbell, Ph.D. ${ }^{1}$, Sachin Pawar, M.D. ${ }^{2}$, and John S. Rhee, \\ M.D. ${ }^{2}$ \\ ${ }^{1}$ Department of Otolaryngology/ Head and Neck Surgery, University of North Carolina, Chapel \\ Hill, North Carolina \\ 2Department of Otolaryngology and Communication Sciences, Medical College of Wisconsin, \\ Milwaukee, Wisconsin
}

\section{Abstract}

Objective-To study the effects of nasal deformity on aerosol penetration past the nasal valve (NV) for varying particle sizes using sprays or nebulizers.

Study Design—Computed mathematical nasal airway model.

Setting-Department computer lab

Subjects and Methods-Particle deposition was analyzed using a computational fluid dynamics model of the human nose with leftward septal deviation and compensatory right inferior turbinate hypertrophy. Sprays were simulated for $10 \mu \mathrm{m}, 20 \mu \mathrm{m}, 50 \mu \mathrm{m}$, or particle sizes following a Rosin Rammler Particle Size Distribution $(10-110 \mu \mathrm{m})$, at speeds of $1 \mathrm{~m} / \mathrm{s}, 3 \mathrm{~m} / \mathrm{s}$, or $10 \mathrm{~m} / \mathrm{s}$. Nebulization was simulated for $1 \mu \mathrm{m}, 3.2 \mu \mathrm{m}, 6.42 \mu \mathrm{m}$, or $10 \mu \mathrm{m}$ particles. Steady state inspiratory airflow was simulated at $15.7 \mathrm{~L} / \mathrm{min}$.

Results-Sprays predicted higher NV penetration on the right side for particle sizes $>10 \mu \mathrm{m}$, with comparable penetration on both sides at $10 \mu \mathrm{m}$. Nearly $100 \%$ deposited in the nasal passages for all spray characteristics. Nebulizer predictions showed nearly $100 \%$ of particles $<6.42 \mu \mathrm{m}$ and over $50 \%$ of $6.42 \mu \mathrm{m}$ bypassing both sides of the nose without depositing. Of the nebulized particles that deposited, penetration was higher on the right at $10 \mu \mathrm{m}$, with comparable penetration on both sides at $6.42 \mu \mathrm{m}$. Spray penetration was highest at $10 \mu \mathrm{m}$, with over $96 \%$ penetrating on both sides at 1 and $3 \mathrm{~m} / \mathrm{s}$. Nebulization penetration was also highest at $10 \mu \mathrm{m}$ ( $40 \%$ on the left, $>90 \%$ on the right).

Conclusion-In the presence of a septal deviation, sprays or nebulizers containing $10 \mu \mathrm{m}$ particles may have good penetration beyond the NV. Nebulized particles $<10 \mu \mathrm{m}$ are likely to be respirable. Additionally, spray speeds above $3 \mathrm{~m} / \mathrm{s}$ may limit penetration.

\section{Keywords}

computational fluid dynamics; septal deviation; aqueous spray; nebulizer; particle; deposition; particle size

\footnotetext{
Address Correspondence to: Dennis O. Frank, Ph.D., Department of Otolaryngology / Head and Neck Surgery, University of North Carolina at Chapel Hill, 170 Manning Drive, CB \#7070, Chapel Hill, NC 27599, dennis_frank@med.unc.edu, Phone: (919) 843-6382, Fax: (919) 966-7941.

Part of the work in this manuscript will be presented at the 2011 AAO-HNSF Annual Meeting in San Francisco
} 


\section{Introduction}

Topical drug administration into the nasal cavity has become a widely prescribed form of delivering medications such as intranasal steroids for the treatment of sinonasal inflammatory, allergic, and infectious disorders. Topical nasal medication targets affected sites with minimal systemic absorption, minimizing the risk of systemic side effects and the development of antibiotic resistance in non-targeted areas. ${ }^{1}$

Intranasal medications are usually administered by nasal drops, aqueous spray pumps, and nebulizers. Spray pumps are most commonly used ${ }^{2,3}$ despite the fact that experimental studies have shown many spray devices deposit a significant amount of their drug in the anterior, less metabolically active regions of the nasal cavity. ${ }^{3-6}$ This anterior deposition is probably due to inertial impaction since most spray pumps are designed to release a large proportion of aerosol particles greater than $20 \mu \mathrm{m}$ which exit the devices at a relatively rapid speed when actuated.

A number of studies have suggested that nasal nebulization is a more effective method of delivering topical medication beyond the nasal valve region than aqueous spray pumps. . $^{2,3,5,7}$ This enhanced penetration is attributed to the fact that nebulizers are designed to generate small, slow moving particles that traverse the nasal cavity at a resting breathing rate, thereby minimizing inertial impaction anterior to the nasal valve.,

In addition to the delivery device, a combination of other factors can also contribute to the efficacy of intranasal medications. These include drug formulation characteristics, site of deposition, underlying sinonasal medical condition, patient technique in the use of the delivery device, and nasal anatomy. ${ }^{8,9}$ Human nasal anatomy is particularly significant since it is characterized by variations across individuals which can be accentuated by disease. In particular, the presence of nasal anatomic deformities such as septal deviation may severely impede particle transport.

Recent advances in computational technology have made computer simulation a viable way to provide consistent objective measures of nasal airflow and function. Computational fluid dynamics (CFD) techniques can be used to simulate the flow of air, estimate drug delivery through three-dimensional (3D) reconstructions of the nasal cavity A number of validated CFD studies of nasal spray deposition have been conducted, ${ }^{4,10-15}$ indicating that these methods can be used to make reliable predictions.

However, none of these studies investigated the effects of nasal deformity and particle size on nebulized aerosol deposition pattern in the nasal cavity. The objective of the present study, therefore, was to use CFD techniques to compare drug delivery penetration past the nasal valve of aqueous spray pumps and nebulizers in a patient with nasal airway obstruction (NAO) due to septal deviation.

\section{Materials and Methods}

\section{Nasal Model Construction}

A three-dimensional (3D) nasal airway model of a 30-year-old Caucasian female subject (weight, $86.4 \mathrm{~kg}$; height, $164.6 \mathrm{~cm}$ ) with a moderate to severe leftward septal deviation and a compensatory right inferior turbinate hypertrophy (Fig. 1A) was created from CT scans containing 142 slices, with an increment of $0.625 \mathrm{~mm}$, and a pixel size of $0.313 \mathrm{~mm}$. The subject provided informed consent as required and approved by the Institutional Review Board at Medical College of Wisconsin. The CT scan files were imported into the medical imaging software Mimics ${ }^{\mathrm{TM}} 13.1$ (Materialise, Inc., Plymouth, MI), which was used to 
create a 3D reconstruction of the main nasal airways from which the paranasal sinuses were omitted. The 3D reconstruction was exported from Mimics TM in STL file format into the CAD and mesh generating software package ICEM-CFD ${ }^{\text {TM }} 12.1$ (ANSYS, Canonsburg, PA). Planar nostril and outlet surfaces as well as regions for tracking particle deposition in the nasal cavity were constructed (Fig. 1B). The nasal cavity was separated into the following regions:

- Left and Right Anterior Lateral Wall

- Left and Right Anterior Septum

- Left and Right Middle Lateral Wall

- Left and Right Middle Septum

- Nasopharynx

The anterior regions ranged from the nostrils up to the nasal valve area; the middle regions covered the turbinates and adjacent nasal septum, and the nasopharynx was defined as posterior to the turbinates and septum.

\section{Drug Delivery Methods}

To simulate the administration of topical medication into each nostril, simulations were configured to mimic drug delivery characteristics of aqueous spray pumps and nebulizers. The spray device attributes and particle sizes considered in this study were within the range represented by typical features of nasal sprays that have been widely studied in the literature. ${ }^{4,6,10,16}$ Thus simulations were conducted using spray speeds of $1 \mathrm{~m} / \mathrm{s}, 3 \mathrm{~m} / \mathrm{s}$, or $10 \mathrm{~m} / \mathrm{s}$, emitted at a plume angle of $68^{\circ}$. Three different monodisperse sprays and a polydisperse spray were simulated. The monodisperse spray simulations used particle sizes of $10 \mu \mathrm{m}, 20 \mu \mathrm{m}$, and $50 \mu \mathrm{m}$, respectively, and the polydisperse simulation used a particle size distribution described by a Rosin Rammler Particle Size Distribution (RRPSD) ${ }^{17}$ set to range in aerodynamic diameter from 10 to $110 \mu \mathrm{m}$ with mean diameter of $66 \mu \mathrm{m}$ and spread distribution parameter of $2.89 \mu \mathrm{m}$. The spray characteristics and particle sizes defined by RRPSD resemble the Pfeiffer PF-80 spray pump presented in Cheng et al. ${ }^{16}$ The location at which simulated sprays were released was defined in the nasal vestibule to be $0.5 \mathrm{~cm}$ into the nose from the nostril surface and was directed laterally or to the side, away from the septum and toward the outer portion of the eye as recommended by Benninger et al. ${ }^{18}$

Simulated nebulization was set up to mimic drug delivery by standard nebulizer devices manufactured by Sinus Dynamics ${ }^{\mathrm{TM}}$ (General Home Pharmacy, Inc, Westlake Village, CA), ViaNase $^{\mathrm{TM}}$ (Kurve Technology, Inc, Lynnwood, WA), or a respiratory tube connected to a nasal pillow mask (Puritan-Bennett, Pleasanton, CA) ${ }^{1}$. Nebulizers were simulated using four different monodisperse particle sizes, $1 \mu \mathrm{m}, 3.2 \mu \mathrm{m}, 6.42 \mu \mathrm{m}$, or $10 \mu \mathrm{m}$. The $1 \mu \mathrm{m}$ and $3.2 \mu \mathrm{m}$ sizes were chosen based on information available from advertising material from Sinus Dynamics $^{\mathrm{TM}}$, while $6.42 \mu \mathrm{m}$ and $10 \mu \mathrm{m}$ have been discussed in the literature. ${ }^{1,3}$ The transport of aerosolized particles by spray pump or nebulizer was simulated with the head held upright in a neutral position at about $0^{\circ}$ to the vertical plane.

\section{Numerical Simulation of Airflow and Particle Trajectories}

In order to solve the equations that govern fluid flow, a computational mesh of the nasal airspaces was created in ICEM-CFD ${ }^{\mathrm{TM}}$ using approximately 4 million graded tetrahedral elements with a three-layer prism-element boundary at the airway walls. Steady-state, laminar inspiratory airflow was simulated using the CFD software package Fluent ${ }^{\mathrm{TM}}$ 12.1.4 (ANSYS, Inc., Canonsburg, PA) under pressure-driven conditions. The boundary conditions specified in Fluent ${ }^{\mathrm{TM}}$ to determine the airflow field were defined as follows: (1) a no-slip 
"wall" condition at the airway walls with the assumption that the walls were stationary with zero air velocity at the air-wall interface, (2) a "pressure-inlet" condition at the nostrils with gauge pressure set to zero, and (3) a "pressure-outlet" condition at the outlet with gauge pressure set to -25.4 Pascals $(\mathrm{Pa})$ that generated a target steady-state flow rate of $15.7 \mathrm{~L} / \mathrm{min}$. This flow rate was twice the minute volume (amount of air inhaled in $1 \mathrm{~min}$, defined as tidal volume times respiratory rate) which was estimated from body weight using gender-specific power law curves. ${ }^{19}$

Particle trajectories were calculated using the Discrete Phase Model in Fluent ${ }^{\mathrm{TM}}$, assuming unit density and that particles were spherical, until each aerosolized particle deposited or exited the nasal cavity at the nasopharynx. Those particles that exited through the outlet at the nasopharynx will be categorized as "escaped." This study did not track the final destination of particles that escaped the nasal cavity. For particles that deposited in the nasal cavity, the region where each particle deposited was tracked, and penetration percentage past the nasal valve area was estimated as follows:

$$
\text { Penetration past nasal valve }=\frac{\mathrm{MS}+\mathrm{ML}+\mathrm{N}}{\mathrm{T}} \times 100 \%,
$$

where $M S, M L$, and $N$ represent number of particles deposited on the middle septum, middle lateral wall, and nasopharynx, respectively. $T$ is total number of particles released from the delivery device. A modified form of "difference to sum ratio" was used to express posterior aerosol penetration between the number of particles that deposited on the middle lateral and septal walls. The equation for expressing this ratio (in percent) is given as:

$$
\text { Lateral and Septal Walls Deposition Ratio(LSWDR })=\frac{M L-M S}{M L+M S+N} \times 100 \% \text {, }
$$

$M S, M L$, and $N$ are as defined above; a positive LSWDR value indicates higher aerosol deposition on the lateral wall than on the septum. Particles that exited the nasal passage via the nasopharynx were expressed as:

$$
\text { Escaped Particles }=\frac{E}{T} \times 100 \% \text {. }
$$

Here $E$ is the number of particles that exited the nasal cavity at the nasopharynx, and $T$ is as defined above.

To simulate aqueous spray pumps, the "solid cone" injection type was specified in Fluent" which generated particle trajectories that emanated from the spray release position at randomly dispersed angles within the spray cone region. Nebulizers were simulated by specifying "surface" as injection type and choosing a cross-sectional area at the nostrils from which to release aerosolized particles. Analysis and visualization of results were conducted using Fluent TM $^{\mathrm{TM}}$ and the post-processing software package Fieldview ${ }^{\mathrm{TM}} 12$ (Intelligent Light, Lyndhurst, PA).

\section{Results}

Fig. 2 shows a wide variation in posterior aerosol penetration in the nasal cavity for different characteristics of the drug delivery device. Spray pump particle penetration past the nasal valve was greatest at $10 \mu \mathrm{m}$, with over $96 \%$ posterior penetration at spray speed of 1 or $3 \mathrm{~m} / \mathrm{s}$. 
CFD simulation results showed a significantly higher lack of aerosol penetration on the affected (left) side which was most dramatic for larger particle sizes (spray pump $>20 \mu \mathrm{m}$, and nebulizer with $10 \mu \mathrm{m}$ ). This implies that the likelihood of inertial impaction is enhanced by nasal anatomic deformity.

From Fig. 2, it can be seen that nebulized posterior aerosol penetration was less than $4 \%$ on both sides of the nose at 1 and $3.2 \mu \mathrm{m}$. Predicted penetration was highest at $10 \mu \mathrm{m}$, with $96 \%$ aerosol deposition recorded on the right side, and $40 \%$ deposition on the affected side. Simulated results in Fig. 3 showed that nebulizers increased the number of escaped particles from the nasal cavity; $97 \%$ of particles of size $1 \mu \mathrm{m}$ exited via the nasopharynx. Similarly, more than $94 \%$ and $59 \%$ of particles of sizes $3.2 \mu \mathrm{m}$ and $6.42 \mu \mathrm{m}$, respectively were predicted to have escaped. In general, the presence of a septal deviation on the affected did not negatively impact the rate at which particles exited the nasal cavity.

Posterior septal wall deposition was considerable higher with aqueous spray pumps on both sides of the nasal cavity than nebulizers (Fig. 4). Topical medications released at $1 \mathrm{~m} / \mathrm{s}$ spray speed showed considerably more septal wall deposition, $>94 \%$, than other spray speeds. In addition, septal deviation enhanced particle deposition onto the septum. Drugs sprayed at $3 \mathrm{~m} / \mathrm{s}$ or $10 \mathrm{~m} / \mathrm{s}$ produced greatest lateral wall deposition on the unaffected side for $10 \mu \mathrm{m}$ and $20 \mu \mathrm{m}$ particle. CFD simulations predicted more lateral wall deposition on both sides of the nasal cavity during nebulization of $1 \mu \mathrm{m}$ and $3.2 \mu \mathrm{m}$ particles (Fig. 4). The results suggested that nebulized aerosol particles were more likely to deposit on the lateral wall than sprayed particles. Furthermore, particle deposition on the lateral wall during nebulization was negatively impacted by the presence of a septal deflection.

Simulated nebulizers showed a widespread deposition pattern with extensive surface area coverage (Fig. 5). However, a large portion of these particles bypassed the nasal airway with smaller particle sizes exiting the nose at a high rate (Fig. 3). Posterior aerosol deposition was predicted to be increased on the unaffected (right) side relative to the affected side (Figs. 3 and 5). Also, the unaffected side appeared to have more deposition around the middle meatus when drug delivery is by an aqueous spray pump.

\section{Discussion}

Previous studies examining topical nasal drug administration by nebulizers in anatomically correct subjects have generally reported increased aerosolized particle deposition past the anterior nasal cavity compared to aqueous spray pumps. ${ }^{2,3,5}$ Both Kundoor et al. ${ }^{2}$ and Suman et al. ${ }^{3}$ suggested that nasal nebulizers covered greater surface area. CFD simulation results indicated that the assertion of better posterior particle deposition by nebulizers might be misleading, at least for an anatomically deformed subject. Whereas the results of this preliminary study appeared consistent with what has been reported in the literature about nebulizers creating considerable more particle penetration past the nasal valve area, it appears most of these particles are not retained in the nasal cavity, rather they exited via the nasopharynx. In their 1998 paper, Suman and colleagues reported that drug delivery by nasal nebulizers could enhance particle deposition in the pharynx and lungs compared to aqueous sprays, and their 1999 paper suggested that lung deposition is the result of particle size within the range $2-10 \mu \mathrm{m}$.

The results presented in this study showed that aqueous spray pumps generally achieve more aerosol posterior deposition in the nasal cavity relative to nebulizers. Septal deviation did not impact particle transport for $10 \mu \mathrm{m}$ particles when administer by spray pumps. This trend was not observed for the larger particle sizes for which noticeable penetration discrepancies were observed between both sides. In addition, aerosol penetration increased at slower spray 
speeds. Simulations predicted that posterior aerosol retention in the nasal cavity increased exponentially with larger particle sizes (from $1 \mu \mathrm{m}$ to $10 \mu \mathrm{m}$ ) during nebulization, particularly on the unaffected side. Highest aerosol penetration occurred at the $10 \mu \mathrm{m}$ particle size on both sides of the nose with both simulated delivery devices.

CFD has several advantages over other methods to assess nasal deposition such as scintigraphy, endoscopic visualization with aerosolized dye, computed tomography (CT) imaging with contrast medium, or quantification of radioactivity with surgical compresses. First, patients are not exposed to any radiation other than diagnostic CT scans. Second, quantitative, regional deposition patterns can be obtained to a much greater accuracy than is possible with other methods. Third, extensive studies of particle deposition effects of many spray and delivery device characteristics, as well as patient-use factors such as head position, nozzle insertion, and breathing behaviors, can be conducted far more quickly and cost-effectively than is possible using in vivo methods due to limitations on the number of subjects and trials in each subject that can be studied.

There are a number of potential clinical implications of this study. Simulations suggested that the correction of a septal deviation may greatly enhance drug delivery. The clinical scenario of a patient with an underlying mucosal inflammatory process - e.g. rhinitis, sinusitis - coupled with an anatomical nasal deformity is a common one. Surgical correction of an underlying anatomic deformity may greatly increase the efficacy of medical management. On the other hand, a temporary pre-surgical management strategy for the treatment of such inflammation should involve topical medications capable of generating small aerosolized particles in the neighborhood of $10 \mu \mathrm{m}$ if aqueous spray is to be prescribed. In addition, these results suggest that patients may be advised not to spray medication forcefully as this seems to limit penetration of the drug. Similarly, if drugs are to be administered by nebulization, a system that generates particles with optimal mass median aerodynamic diameter greater than $6.42 \mu \mathrm{m}$ may improve aerosol retention in the nose.

Although this study identified and quantified the potential effects of a moderate to severe septal deviation and particle size characteristics on topical intranasal medication, our airflow simulations were limited to laminar, steady-state conditions, meaning that turbulence and the cyclic nature of airflow were not modeled. Furthermore, these results reflect the nasal anatomy of a single subject with some evidence of nasal cycling which this preliminary study did not account for. In the future, a cohort of patients experiencing NAO with interindividual differences in nasal anatomy will be compared pre- and post-operatively.

\section{Acknowledgments}

This research was funded by grants R01EB009557 and R01EB009557-01S1 from the National Institutes of Health/ National Institute of Biomedical Imaging and Bioengineering, under subcontract to the University of North Carolina from the Medical College of Wisconsin. This description of results from this research is solely the responsibility of the authors and does not represent the official views of the NIH. The authors thank Nicole Stelse for her contributions to this work.

\section{References}

1. Hilton C, Wiedmann T, St Martin M, et al. Differential deposition of aerosols in the maxillary sinus of human cadavers by particle size. Am J Rhinol. 2008; 22:395-398. [PubMed: 18702904]

2. Kundoor V, Dalby RN. Assessment of nasal spray deposition pattern in a silicone human nose model using a color-based method. Pharm Res. 2010; 27:30-36. [PubMed: 19902337]

3. Suman JD, Laube BL, Dalby R. Comparison of nasal deposition and clearance of aerosol generated by nebulizer and an aqueous spray pump. Pharm Res. 1999; 16:1648-1652. [PubMed: 10554112] 
4. Kimbell JS, Segal RA, Asgharian B, et al. Characterization of deposition from nasal spray devices using a computational fluid dynamics model of the human nasal passages. J Aerosol Med. 2007; 20:59-74. [PubMed: 17388754]

5. Suman JD, Laube BL, Dalby R. Nasal nebulizers versus aqueous spray pumps: a comparison of deposition patterns in human volunteers. Respiratory Drug Delivery. 1998; VI:211-218.

6. Foo MY, Cheng Y-S, Su W-C, Donovan MD. The influence of spray properties on intranasal deposition. J Aerosol Med. 2007; 20:495-508. [PubMed: 18158721]

7. St Martin MB, Hitzman CJ, Wiedmann TS, Rimell FL. Deposition of aerosolized particles in the maxillary sinuses before and after endoscopic sinus surgery. Am J Rhinol. 2007; 21:196-197. [PubMed: 17424879]

8. Merkus P, Ebbens FA, Muller B, Fokkens WJ. Influence of anatomy and head position on intranasal drug deposition. Eur Arch Otorhinolaryngol. 2006; 263:827-832. [PubMed: 16807754]

9. Blaiss MS, Benninger MS, Fronmer L, et al. Expanding choices in intranasal steroid therapy: Summary of a roundtable meeting. Allergy and Asthma Proceedings. 2006; 27:254-264. [PubMed: 16913270]

10. Chen XB, Lee HP, Chong VF, Wang de Y. A computational fluid dynamics model for drug delivery in a nasal cavity with inferior turbinate hypertrophy. J Aerosol Med Pulm Drug Deliv. 2010; 23:329-338. [PubMed: 20804427]

11. Garlapati RR, Lee HP, Chong FH, Wang DY. Indicators for the correct usage of intranasal medications: A computational fluid dynamics study. Laryngoscope. 2009; 119:1975-1982. [PubMed: 19655385]

12. Inthavong K, Ge Q, Se CMK, Yang W, Tu JY. Simulation of sprayed particle deposition in a human nasal cavity including a nasal spray device. Journal of Aerosol Science. 2011; 42:100-113.

13. Inthavong K, Tian ZF, Tu JY, Yang W, Xue C. Optimising nasal spray parameters for efficient drug delivery using computational fluid dynamics. Comp Biol Med. 2008; 38:713-726.

14. Inthavong K, Tian ZF, Li HF, et al. A numerical study of spray particle deposition in a human nasal cavity. Aerosol Sci Technol. 2006; 40:1034-1045.

15. Kleven M, Melaaen MC, Reimers M, et al. Using computational fluid dynamics (cfd) to improve the bi-directional nasal drug delivery concept. Food and Bioproducts Processing. 2005; 83:107117.

16. Cheng YS, Holmes TD, Gao J, et al. Characterization of nasal spray pumps and deposition pattern in a replica of the human nasal airway. J Aerosol Med. 2001; 14:267-280. [PubMed: 11681658]

17. Rosin P, Rammler E. The laws governing the fineness of powdered coal. Journal of the Institute of Fuel. 1933; 7:29-36.

18. Benninger MS, Hadley JA, Osguthorpe JD, et al. Techniques of intranasal steroid use. Otolaryngol Head Neck Surg. 2004; 130:5-24. [PubMed: 14726906]

19. Garcia GJM, Schroeter JD, Segal RA, et al. Dosimetry of nasal uptake of water-soluble and reactive gases: A first study of interhuman variability. Inhal Toxicol. 2009; 21:607-618. [PubMed: 19459775] 


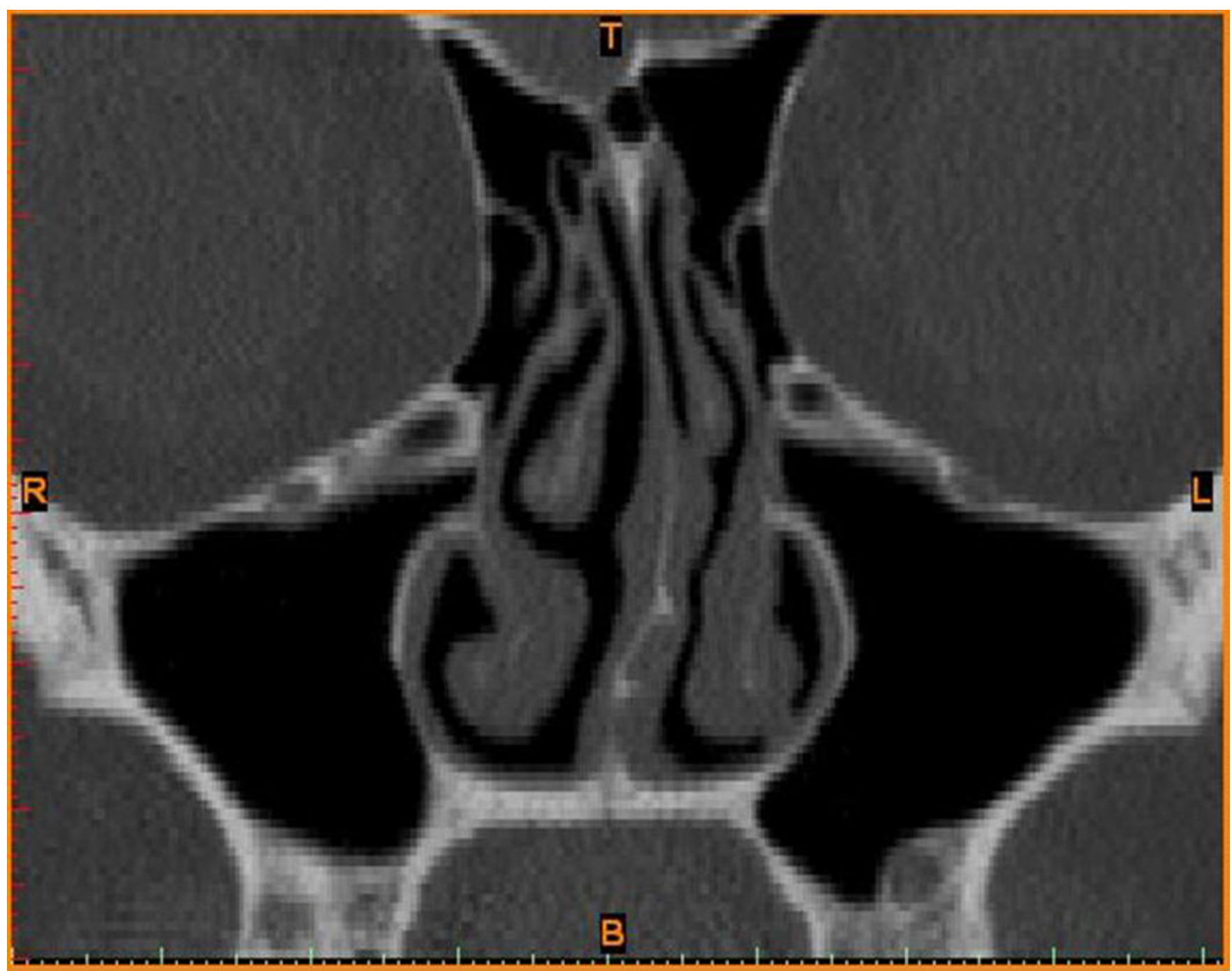




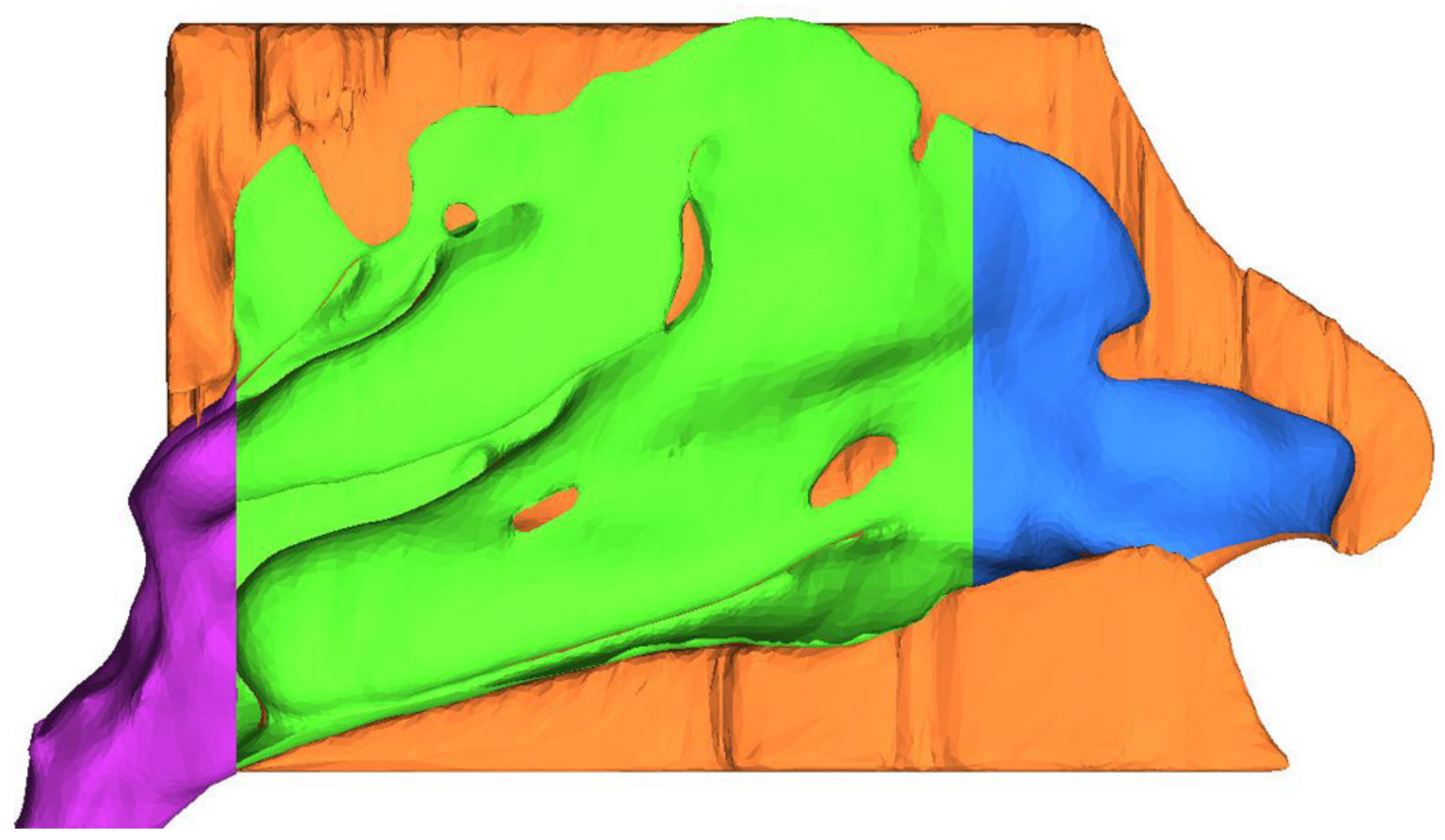

FIGURE 1.

A. Coronal view showing leftward septal deviation.

B. Sagittal view of the left lateral wall of the nasal cavity reconstruction showing regions used for tracking particle deposition (blue, anterior; green, middle; purple, posterior). 


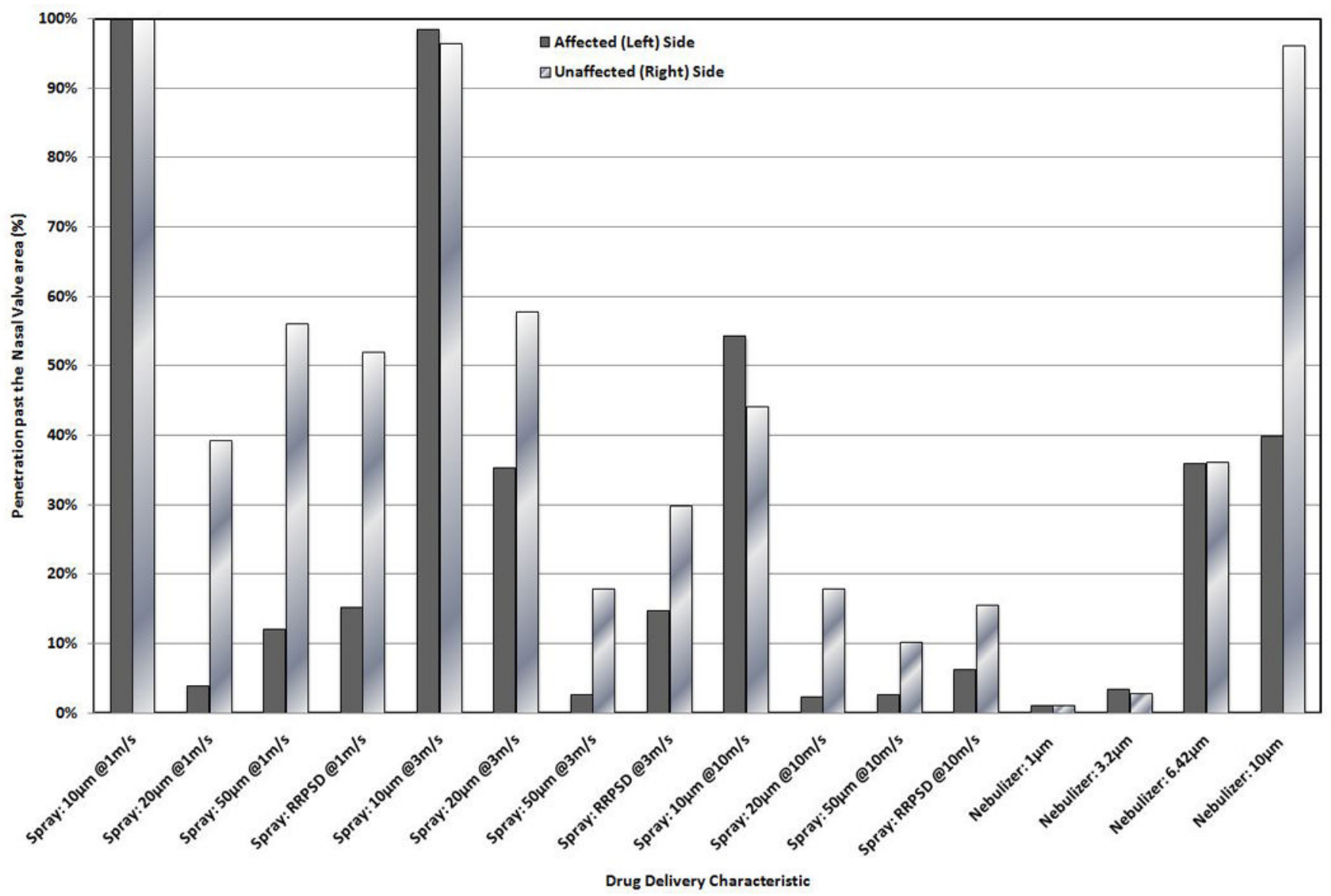

FIGURE 2.

Particle penetration past the naval valve area as predicted by varying the spray, and nebulizer characteristics. 


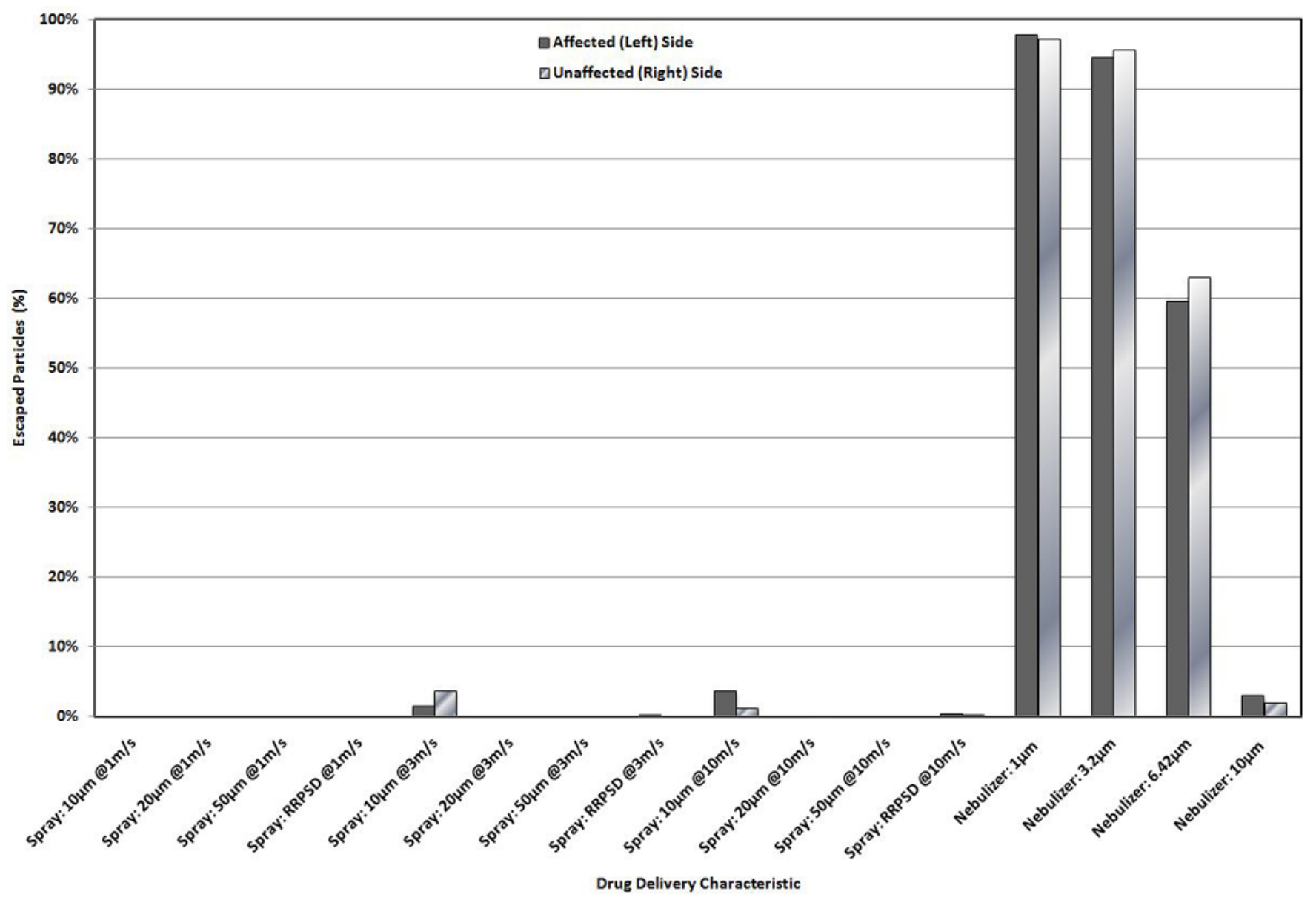

FIGURE 3.

Escaped particles as predicted by varying the spray, and nebulizer characteristics. 


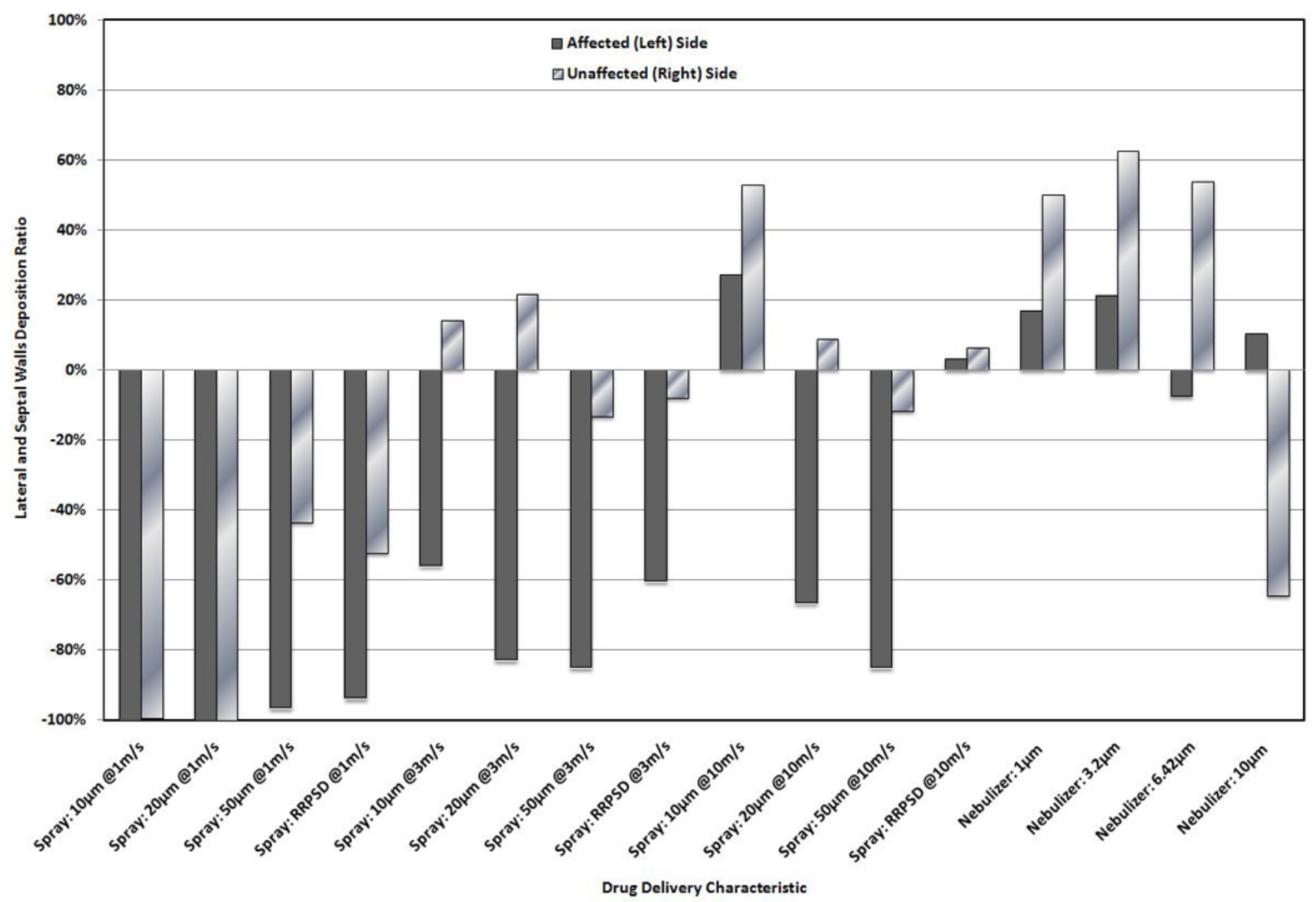

FIGURE 4.

Lateral and Septal walls "difference to sum" penetration ratio. A positive LSWDR value indicates higher deposition on the lateral wall. 


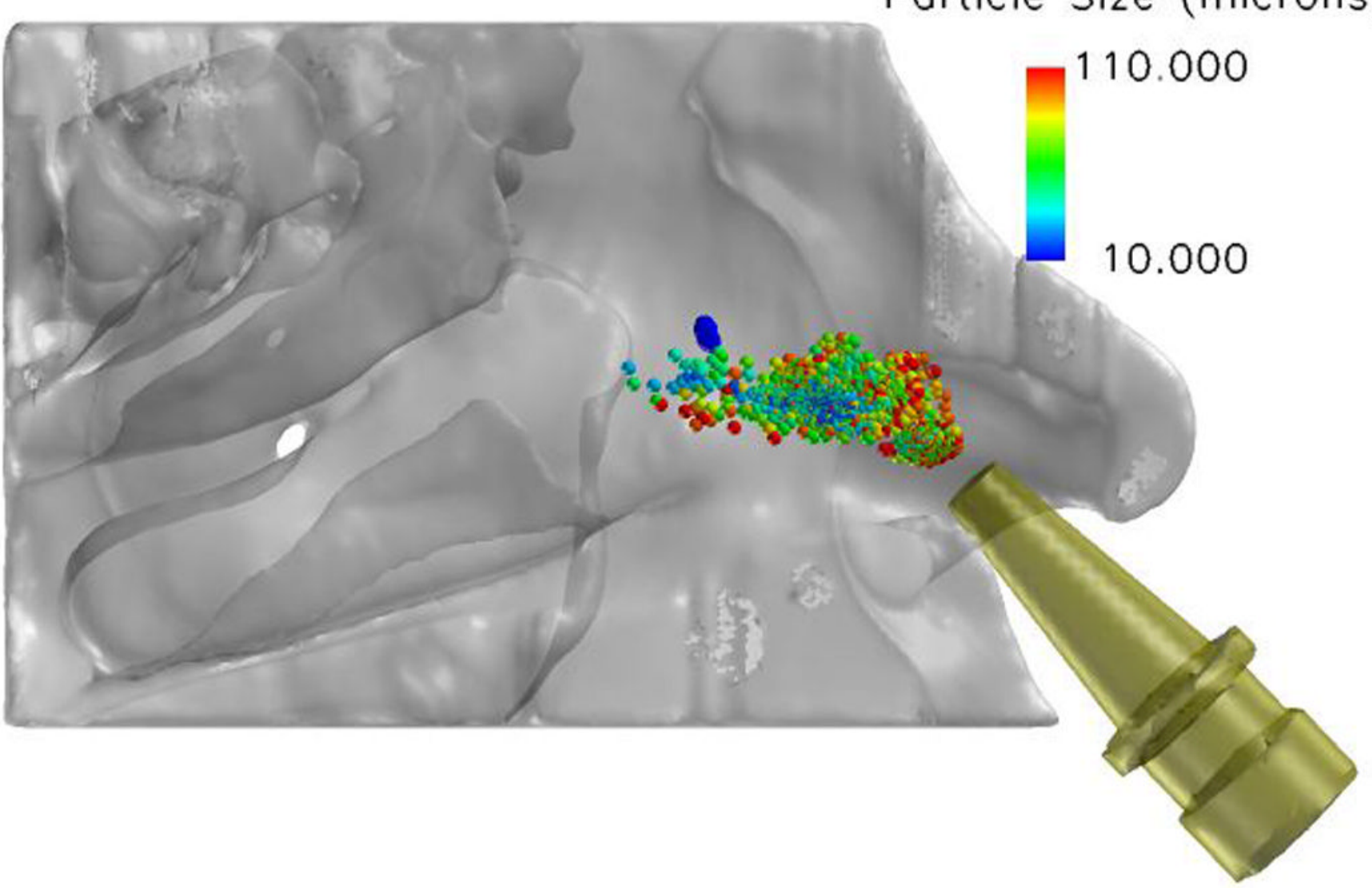


Particle Size (microns)
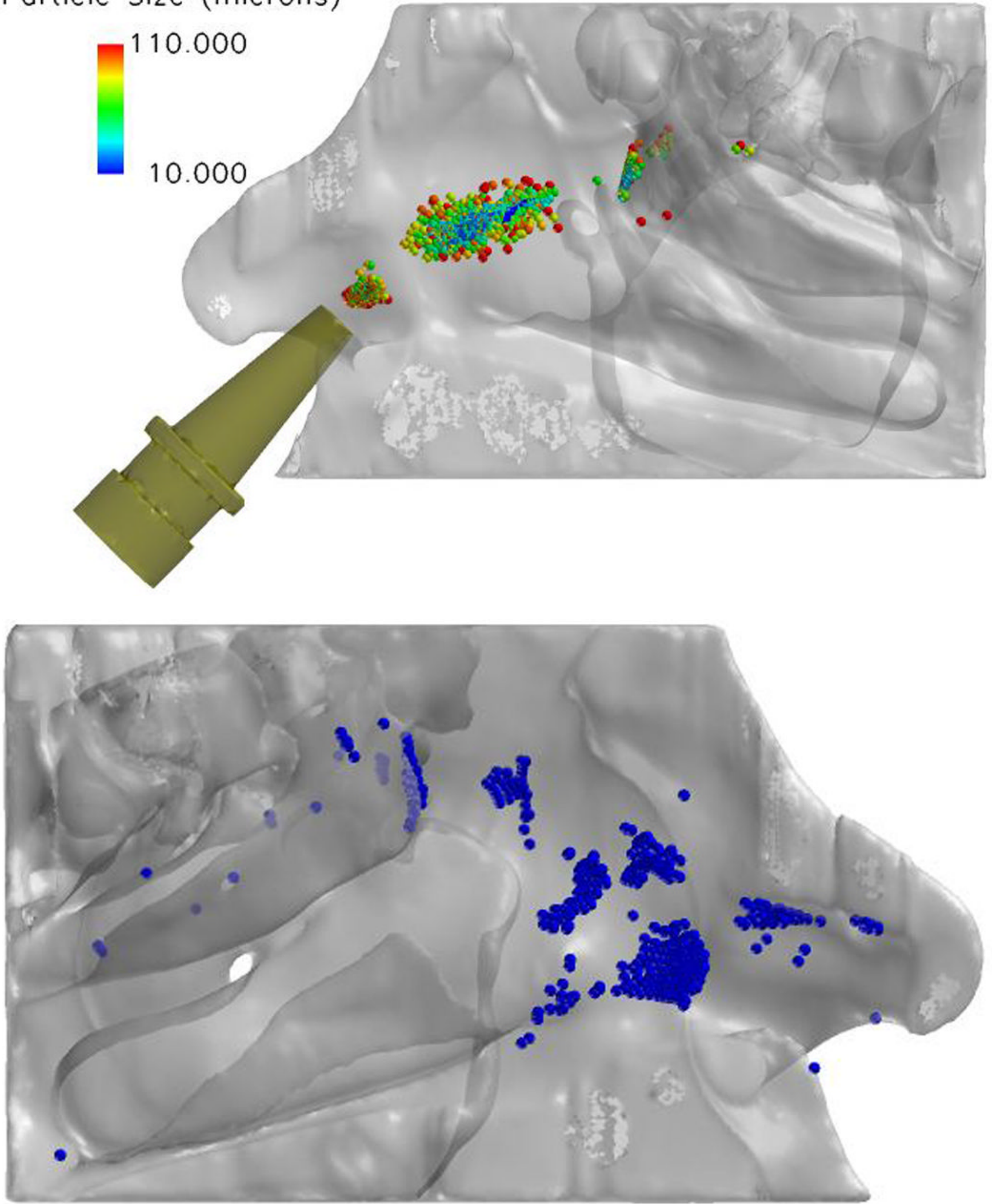


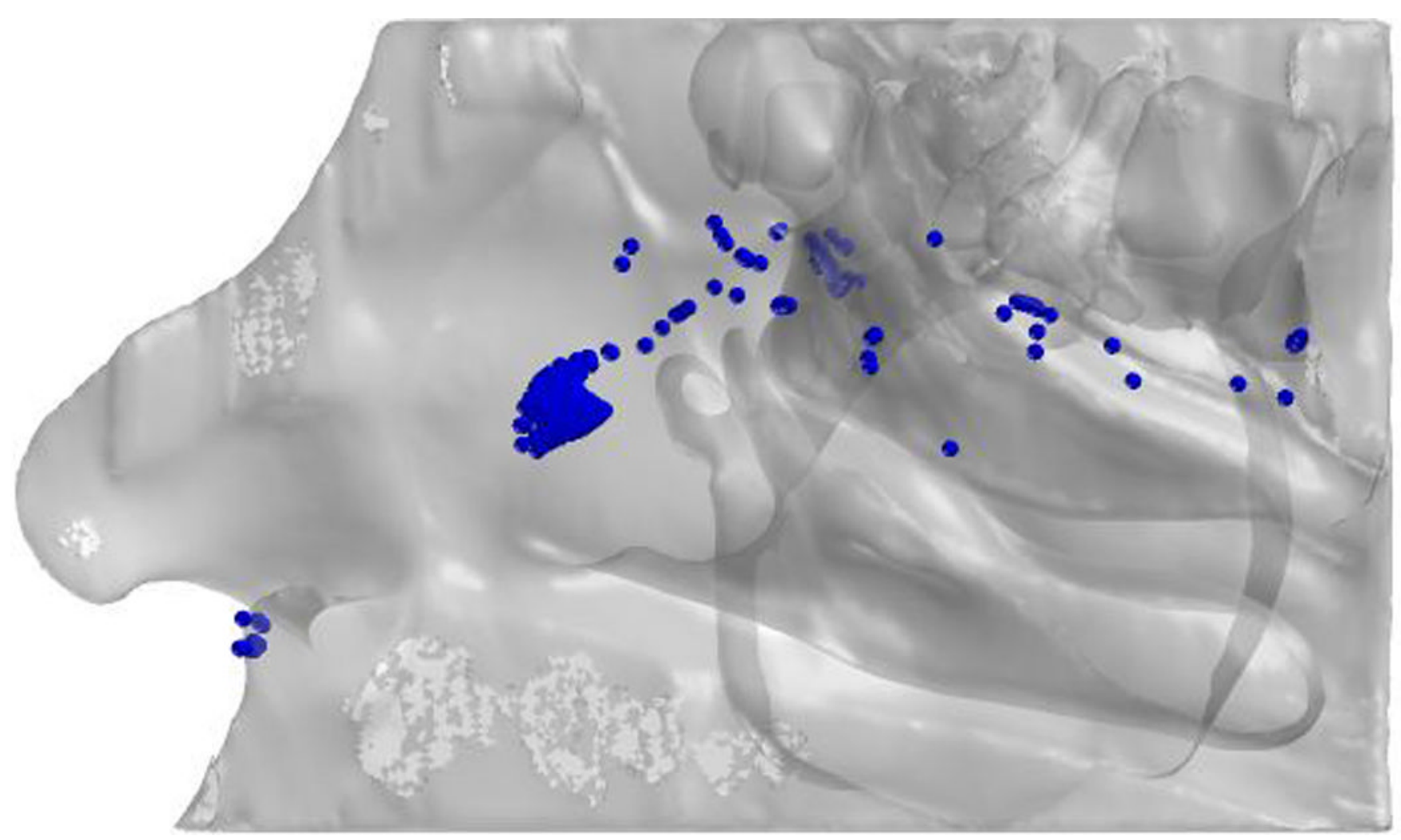

\section{FIGURE 5 .}

A. Simulated spray deposition pattern on the affected side using RRPSD released at a speed of $1 \mathrm{~m} / \mathrm{s}$.

B. Simulated spray deposition pattern on the right (unaffected) side using RRPSD released at a speed of $1 \mathrm{~m} / \mathrm{s}$.

C. Simulated nebulized particle deposition pattern on the deviated side, $10 \mu \mathrm{m}$ particles released from the left nostril.

D. Simulated nebulized particle deposition pattern on the unaffected side, $10 \mu \mathrm{m}$ particles released from the right nostril. 